\title{
Reconfigurable SiGe Low-Noise Amplifiers With Variable Miller Capacitance
}

\author{
Yu-Che Yang, Po-Wei Lee, Hung-Wei Chiu, Yo-Sheng Lin, Senior Member, IEEE, Guo-Wei Huang, and \\ Shey-Shi Lu, Senior Member, IEEE
}

\begin{abstract}
A new input matching method making use of shunt-shunt feedback capacitance is introduced. Based on the new input matching method, reconfigurable SiGe low-noise amplifiers (LNAs) by varying shunt-shunt feedback capacitance are proposed. Two approaches are used to vary the shunt-shunt feedback capacitance. One approach is to switch between two different bias currents while the other is to use a series combination of a switch and a capacitor. Miniaturized fully monolithic reconfigurable SiGe LNAs without emitter degenerative inductors were realized by the above two approaches. The reconfigurable SiGe LNA achieved by switching bias currents only occupies a very small area of $355 \mu \mathrm{m} \times 155 \mu \mathrm{m}$, excluding measurement pads. This LNA achieves an input return losses $\left(S_{11}\right)$ of $-27.6 \mathrm{~dB}$, a voltage gain $\left(A_{v}\right)$ of $19.8 \mathrm{~dB}$, and a noise figure (NF) of $3.18 \mathrm{~dB}$ for 2.4-GHz band when biased at a current of $3.8 \mathrm{~mA}$ and can be reconfigured to obtain $A_{v}=20.4 / 20.3 \mathrm{~dB}, S_{11}=-47.1 /-24.6 \mathrm{~dB}$ and $\mathrm{NF}=3.42 / 3.21 \mathrm{~dB}$ for $5.2 / 5.7-\mathrm{GHz}$ band when bias current is switched to $3 \mathrm{~mA}$. In addition, a 2.4/4.9/5.2/5.7-GHz reconfigurable SiGe LNAs for WLAN applications, whose variable shunt-shunt feedback capacitance is controlled by a switch and a capacitor, was also realized.
\end{abstract}

Index Terms-BiCMOS, CMOS, low-noise amplifier (LNA), multiband, reconfigurable, $\mathrm{SiGe}$.

\section{INTRODUCTION}

W IRELESS communication has evolved into a world of multistandards/multiservices with operating frequencies of $900-\mathrm{MHz} / 1.8-\mathrm{GHz} / 1.9-\mathrm{GHz}$ bands for GSM, 1.5-GHz band for GPS and 2.4/5.2/5.7-GHz bands for WLAN. Therefore, it is desirable to combine two or more standards in one mobile unit [1], [2]. The primary challenge in designing multiband transceivers is increasing the functionality of such communication systems while minimizing the number of additional hardware like low-noise amplifiers (LNAs). Typical design strategies

Manuscript received August 6, 2005; revised January 6, 2006 and June 7, 2006. This work was supported by the National Science Council, R.O.C. under Contract NSC94-2215-E-002-032, Contract NSC93-2212-E-002-079, Contract NSC92-2212-E-002-091, Contract 91EC17A05-S10017, and Contract NSC93-2752-E-002-002-PAE. This paper was recommended by Associate Editor A. Wang.

Y.-C. Yang, P.-W. Lee, and S.-S. Lu are with the Graduate Institute of Electronics Engineering and Department of Electrical Engineering, National Taiwan University, Taipei, Taiwan 106, R.O.C. (e-mail: sslu@ntu.edu.tw).

H.-W. Chiu is with the Department of Electronic Engineering and Graduate Institute of Computer and Communication Engineering National Taipei University of Technology, Taipei, Taiwan 106, R.O.C. (e-mail: sslu@ntu.edu.tw).

Y.-S. Lin is with the Department of Electrical Engineering, National Chi Nan University, Puli, Taiwan 545, R.O.C.

G.-W. Huang is with the National Nano Device Laboratories, Hsinchu, Taiwan 300, R.O.C..

Digital Object Identifier 10.1109/TCSI.2006.883846

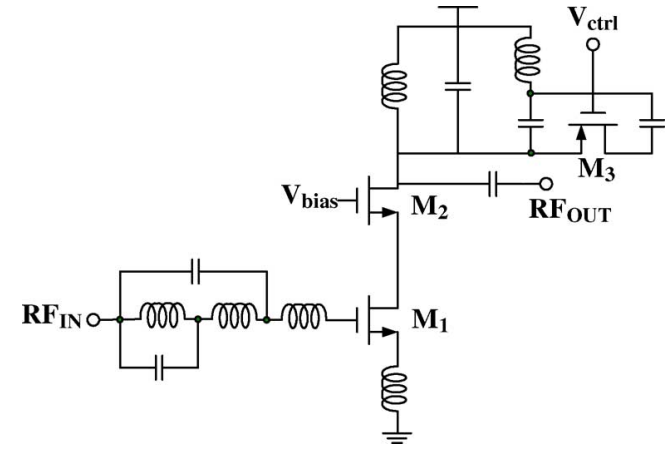

Fig. 1. Pseudo-3 band concurrent CMOS LNA reported in [6].

have used different LNAs for different frequency bands [2]-[4]. However, this way inevitably increases cost, power dissipation and form-factor. Recently, concurrent dual-band LNAs with excellent performances have been devised, but off-chip capacitors and inductors are required [5]. Besides, a concept of pseudo- 3 band concurrent LNA has been proposed [6]. The main drawback of it is that too many inductors are required, which consumes a large chip size (see Fig. 1). In this paper, a new input matching method for LNAs by making use of shunt-shunt feedback capacitance instead of conventional series-series feedback inductor is introduced [7]. This new input matching method is very suitable for reconfigurable LNAs since the capacitance can be varied very easily. Two approaches are used to realize the reconfigurable LNAs. One approach is to change the shunt-shunt feedback capacitance by switching between different bias currents while the other uses a series combination of a switch and a capacitor.

In Section II, the principle of the proposed input matching method is introduced. The concept of dual-feedback circuit methodology is applied to simplify the circuit analysis and then the input impedance $Z_{\mathrm{IN}}$ can be derived [8]. In Section III, we present the design of a reconfigurable SiGe LNA with variable shunt-shunt feedback capacitance achieved by switching bias current, and another reconfigurable SiGe LNA with variable shunt-shunt feedback capacitance controlled by a switch and a capacitor. In Section IV, we demonstrate the measurement results and provide some discussions of the two implemented LNAs. Section V are the conclusions.

\section{PRinciple of InPUt Matching By ShUnT-ShUnT FEEDBACK CAPACITANCE}

Traditionally, an emitter degenerative inductor is used to generate the $50 \Omega$ for input matching [9]. However, the use of inductor inevitably increases the die area. We have developed 


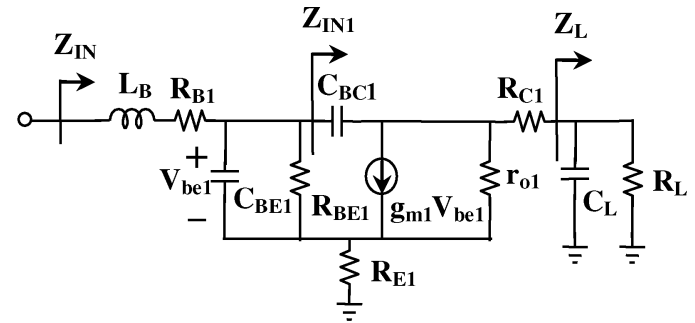

(a)

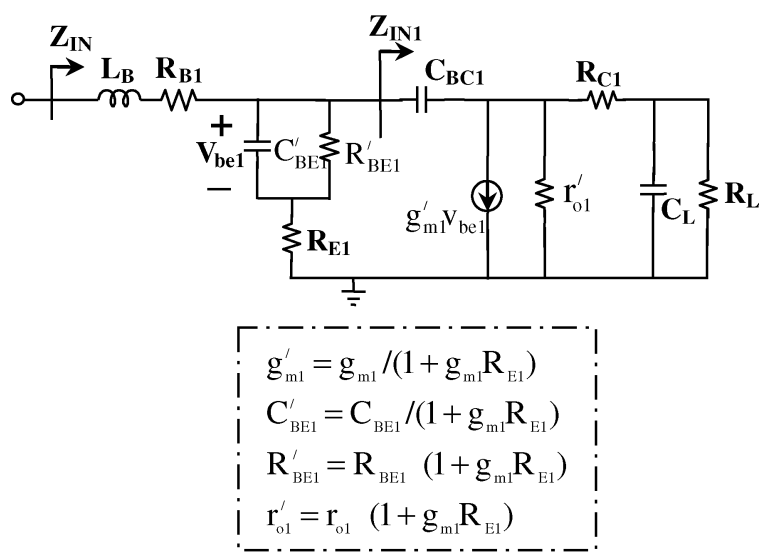

(b)

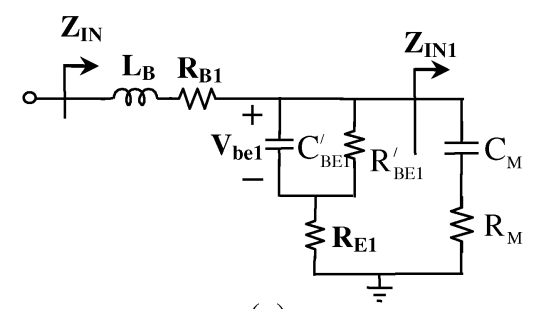

(c)

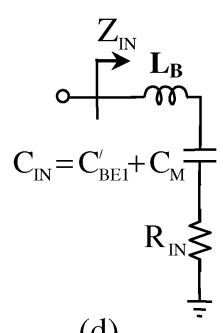

(d)

Fig. 2. Principle of input matching of reconfigurable LNAs using variable shunt-shunt feedback capacitance. (a) Common-emitter amplifier with an input inductor $L_{B}$ and a parallel $R_{L}-C_{L}$ load. (b)-(d) Detailed steps to simplify the equivalent circuit shown in Fig. 2(a) to find the input impedance $Z_{\mathrm{IN}}$.

a new method for input matching, which is explained as follows. Consider a common-emitter amplifier with an input inductor $L_{B}$ and a parallel $R_{L}-C_{L}$ load, as shown in Fig. 2(a). The parallel $R_{L}-C_{L}$ load can be viewed as provided by the parallel combination of the resistive load of the first stage and the input impedance of the following stage of the circuit [see Figs. 3(a) and 4(a)]. By extending the previous work [8], it can be shown that the input impedance $Z_{\mathrm{IN}}$ looking into the input port is equivalent to a series $L_{B}-C_{\mathrm{IN}}-R_{\mathrm{IN}}$ network [see Fig. 2(d)] at some frequency range. The details of the calculation of input impedance $Z_{\mathrm{IN}}$ are as follows. The circuit of Fig. 2(a) can be transformed into that of Fig. 2(b) with some necessary circuit element modifications [8], which are also shown

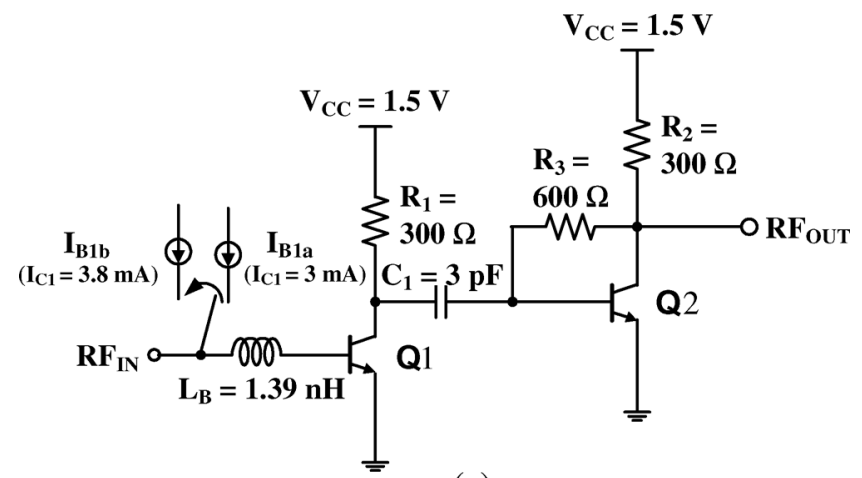

(a)

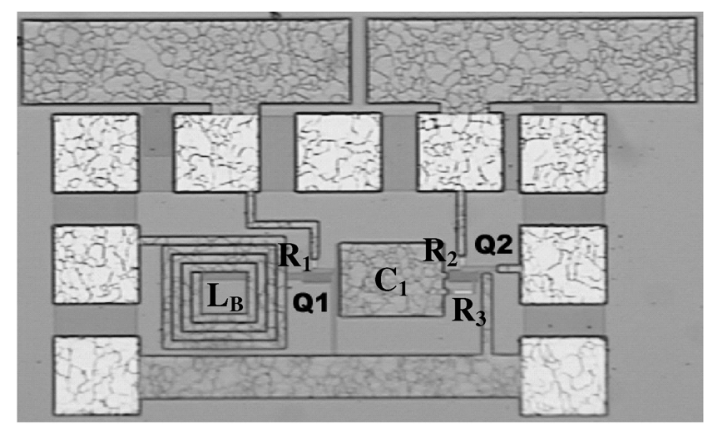

(b)

Fig. 3. (a) Schematic and (b) die photograph of the miniaturized fully monolithic reconfigurable SiGe LNA with variable shunt-shunt feedback capacitance achieved by switching bias currents.

in Fig. 2(b). From Fig. 2(b), the impedance $Z_{\mathrm{IN} 1}$ can be expressed as follows:

$$
\begin{aligned}
Z_{\mathrm{IN} 1} & =\frac{\frac{1}{s C_{B C 1}}+\left(R_{L}^{\prime} \| \frac{1}{s C_{L}^{\prime}}\right)}{1+g_{m 1}^{\prime \prime}\left(R_{L}^{\prime} \| \frac{1}{s C_{L}^{\prime}}\right)} \\
= & \frac{1+s R_{L}^{\prime}\left(C_{L}^{\prime}+C_{B C 1}\right)}{\left(1+g_{m 1}^{\prime \prime} R_{L}^{\prime}\right) s C_{B C 1}+s^{2} C_{L}^{\prime} C_{B C 1} R_{L}^{\prime}}
\end{aligned}
$$

where $g_{m 1}^{\prime \prime}=\left(g_{m 1}^{\prime} \cdot R_{B E 1}^{\prime}\right) /\left(R_{B E 1}^{\prime}+R_{E 1}+s C_{B E 1}^{\prime}\right.$ $\left.R_{B E 1}^{\prime} R_{E 1}\right), R_{B E 1}^{\prime}=R_{B E 1}\left(1+g_{m 1} R_{E 1}\right), C_{B E 1}^{\prime}=C_{B E 1} /$ $\left(1+g_{m 1} R_{E 1}\right), g_{m 1}^{\prime}=g_{m 1} /\left(1+g_{m 1} R_{E 1}\right), R_{\mathrm{o} 1}^{\prime}=$ $R_{\mathrm{o} 1}\left(1+g_{m 1} R_{E 1}\right), C_{L}^{\prime}=C_{L} R_{L} /\left(R_{L}+R_{C 1}\right)$, and $R_{L}^{\prime}=$ $\left(R_{L}+R_{C 1}\right) \| R_{\mathrm{o} 1}^{\prime}$. As shown in Fig. 2(c), $Z_{\mathrm{IN} 1}$ can be simplified as a series $R C$ circuit as follows:

$$
\begin{aligned}
Z_{\mathrm{IN} 1} \approx & \frac{1+s R_{L}^{\prime}\left(C_{L}^{\prime}+C_{B C 1}\right)}{\left(1+g_{m 1}^{\prime} R_{L}^{\prime}\right) s C_{B C 1}+s^{2} C_{L}^{\prime} C_{B C 1} R_{L}^{\prime}} \\
\approx & \left(\frac{R_{L}^{\prime}}{1+g_{m 1}^{\prime} R_{L}^{\prime}}+\frac{g_{m 1}^{\prime} R_{L}^{/ 2}}{\left(1+g_{m 1}^{\prime} R_{L}^{\prime}\right)^{2}} \cdot \frac{C_{L}^{\prime}}{C_{B C 1}}\right) \\
& +\frac{1}{s C_{B C 1}\left(1+g_{m 1}^{\prime} R_{L}^{\prime}\right)} \\
\equiv & R_{M}+\frac{1}{s C_{M}} .
\end{aligned}
$$




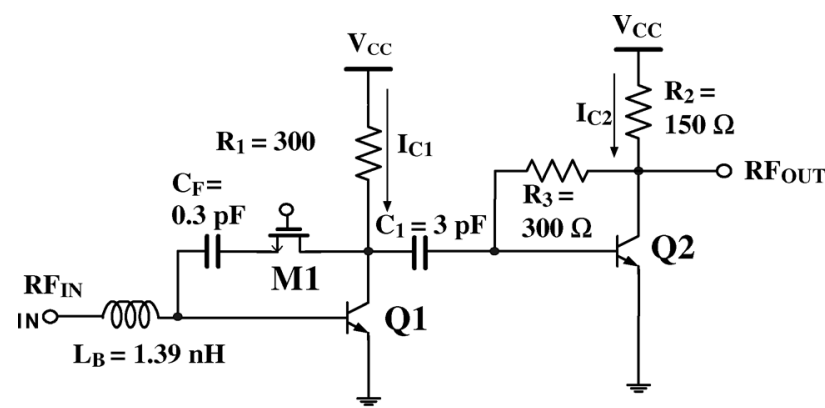

(a)

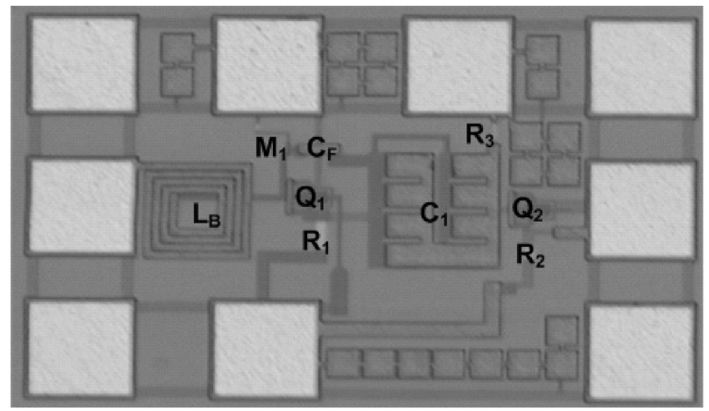

(b)

Fig. 4. (a) Schematic, and (b) die photograph of the miniaturized fully monolithic reconfigurable SiGe LNA with variable shunt-shunt feedback capacitance.

In (2), we assume that $\left(1+g_{m 1}^{\prime} R_{L}\right) \gg \omega_{2} \cdot R_{L}^{2} C_{L}\left(C_{L}+C_{B C 1}\right)$ and $R_{B E 1}^{\prime} \gg\left(R_{E 1}+s C_{B E 1}^{\prime} R_{B E 1}^{\prime} R_{E 1}\right)$, which is usually the case. Finally, the input impedance $Z_{\mathrm{IN}}$ can be expressed as a series $L_{B}-C_{\mathrm{IN}}-R_{\mathrm{IN}}$ circuit as follows [see Fig. 2(d)]:

$$
\begin{aligned}
& Z_{\mathrm{IN}} \approx J \omega L_{B}+\frac{1}{J \omega\left(C_{B E 1}^{\prime}+C_{M}\right)} \\
&+\left(R_{B 1}+R_{M} \cdot\left(\frac{C_{M}}{C_{B E 1}^{\prime}+C_{M}}\right)^{2}\right. \\
&\left.+\frac{R_{B E 1}^{/}}{1+\omega^{2} C_{B E 1}^{/ 2} R_{B E 1}^{/ 2}} \cdot\left(\frac{C_{B E 1}^{\prime}}{C_{B E 1}^{/}+C_{M}}\right)^{2}\right) \\
& \equiv J \omega L_{B}+\frac{1}{J \omega C_{\mathrm{IN}}}+R_{\mathrm{IN}} .
\end{aligned}
$$

$R_{\mathrm{IN}}$ can be adjusted to be nearly $50 \Omega$ by appropriate values of $R_{L}, C_{L}$, transconductance $g_{m 1}$, and base-collector capacitance $C_{B C 1}$, etc.. $C_{\mathrm{IN}}$ is the sum of equivalent base-emitter capacitance $C_{B E 1}^{\prime}$ and Miller capacitance $C_{M}$. The resonant frequency is dominated by $C_{\mathrm{IN}}$ and the input inductor $L_{B} \cdot C_{\mathrm{IN}}$ can be varied by the following two approaches to adjust the resonant frequency.

The first approach to vary $C_{\mathrm{IN}}$ is switching between different base bias currents $I_{B 1}$ (or collector bias currents $I_{C 1}$ ) [see Fig. 3(a)]. $C_{\mathrm{IN}}$ is the sum of $C_{B E 1}^{\prime}$ and $C_{M}$, both of which are functions of $I_{B 1}$ (or $I_{C 1}$ ). Hence, $C_{\mathrm{IN}}$ varies as $I_{B 1}$ (or $I_{C 1}$ ) changes. The resonant frequency determined by $C_{\mathrm{IN}}$ and $L_{B}$ changes accordingly and as a result, the resonant frequency for input matching also varies. That is, one application band can be switched to another application band by simply switching the base current (or collector current) from one bias current to another bias current. Note that the change of $C_{\mathrm{IN}}\left(\right.$ or $C_{M}$ ) with bias current can be substantial because of the beneficial Miller multiplication effect.

The second approach to vary $C_{\mathrm{IN}}$ is adding a series combination of an extra capacitor $C_{F}$ and MOS switch between the base and collector terminals of the input transistor $Q 1$ [see Fig. 4(a)]. By turning on or off the switch, the total shunt-shunt capacitance between the base and collector terminals is changed. Since $C_{\mathrm{IN}}$ is the sum of $C_{B E 1}^{\prime}$ and $C_{M}$, and $C_{M}$ is a function of the total shunt-shunt capacitance between the base and collector terminals, $C_{\mathrm{IN}}$ varies as the total shunt-shunt capacitance between the base and collector terminals changes. Hence, the higher application band can be switched to a lower one depending on the on-off state of the MOS switch.

\section{CIRCUIT DESIGN}

\section{A. Reconfigurable SiGe LNA Achieved by Switching Bias Current}

The reconfigurable LNA shown in Fig. 3(a) was implemented in a standard $0.35-\mu \mathrm{m}$ SiGe BiCMOS heterojunction bipolar transistor (HBT) process provided by the commercial foundry TSMC. Basically, it consisted of two common-emitter amplifiers. Transistor $Q 1$ was preceded with an inductor $L_{B}$ for input impedance matching. Transistor $Q 2$ provided additional gain as well as output matching, if necessary, by using a local shunt-shunt feedback resistor $R_{3}$ around it. Note that resistive loads $R_{1}$ and $R_{2}$ instead of $L C$ tuned loads were used to minimize the die area. The circuit parameters were: $L_{B}=1.39 \mathrm{nH}$, $R_{1}=R_{2}=300 \Omega, R_{3}=600 \Omega$, and $C_{1}=3 \mathrm{pF}$. Both transistors $Q 1$ and $Q 2$ had the same emitter size of $0.3 \mu \mathrm{m} \times 20.3 \mu \mathrm{m} \times 2$ emitter fingers. Fig. 3(b) shows the die photograph of the reconfigurable SiGe LNA achieved by switching bias current. The circuit (excluding the patterns for testing) only occupied a very small area of $355 \mu \mathrm{m} \times 155 \mu \mathrm{m}$ because only a very small value $(1.39 \mathrm{nH})$ inductor $L_{B}$ was used.

An analytical expression of the load impedance $Z_{L}(=$ $\left.R_{L} \|\left(1 / s C_{L}\right)\right)$ seen at the collector terminal of transistor $Q 1$ of the LNA shown in Fig. 3(a) is derived in the Appendix. The desired values of $C_{L}$ and $R_{L}$ can be obtained by appropriate values of $R_{1}, R_{2}, R_{3}$, transconductance $g_{m 2}$, and base-collector capacitance $C_{B C 2}$, etc.. From (1)-(3), the equivalent input capacitance $C_{\mathrm{IN}}$ of the LNA in Fig. 3(a) can be expressed as a function of $I_{B 1}$ (or $I_{C 1}$ ) as follows:

$$
\begin{aligned}
C_{\mathrm{IN}} & \approx C_{B E 1}^{\prime}+C_{B C 1}^{\prime}\left(1+g_{m 1}^{\prime} R_{L}^{\prime}\right) \\
& \approx C_{B E 1}^{+} C_{B C 1}\left(1+g_{m 1} R_{L}^{\prime}\right) \\
& =C_{B E 1}+C_{B C 1}\left(1+\frac{\beta I_{B 1}}{V_{\mathrm{T}}} R_{L}^{\prime}\right) \\
& =C_{B E 1}+C_{B C 1}\left(1+\frac{\beta I_{B 1}}{V_{\mathrm{T}}} R_{L}^{\prime}\right) .
\end{aligned}
$$

Hence, $C_{\mathrm{IN}}$ increases as $I_{B 1}$ (or $I_{C 1}$ ) increases. The resonant frequency determined by $C_{\mathrm{IN}}$ and $L_{B}$ decreases accordingly and as a result, the resonant frequency for input matching also 
decreases. That is, the higher application band can be switched to a lower one by simply switching the base current (or collector current) from a lower bias current to a higher bias current. Note the reconfigurable LNA architecture, which is achieved by switching bias current, is not suitable for the CMOS technology. This is because its equivalent input capacitance (or $g_{m}$ ) is not strongly dependent on its bias current.

\section{B. Reconfigurable SiGe LNA Controlled by a Switch and a Capacitor}

Fig. 4(a) shows the circuit diagram of a SiGe reconfigurable LNA, which was basically the same as that of Fig. 3(a) except that a series combination of a MOS switch M1 and a capacitor $C_{F}$ was added between the base and collector terminals of the input transistor. The circuit parameters were: $L_{B}=1.39 \mathrm{nH}, R_{1}=300 \Omega, R_{2}=150 \Omega$, $R_{3}=300 \Omega, C_{1}=3 \mathrm{pF}, C_{F}=0.3 \mathrm{pF}$, emitter size of $Q_{1}$ and $Q_{2}=0.3 \mu \mathrm{m} \times 20.3 \mu \mathrm{m} \times 2$ fingers, M1: $W / L=30 / 0.35 \mu \mathrm{m} / \mu \mathrm{m}$. Fig. 4(b) shows the die photo of the reconfigurable SiGe LNA with variable shunt-shunt capacitance controlled by a MOS switch and a capacitor. This circuit was also implemented in a $0.35-\mu \mathrm{m}$ SiGe BiCMOS HBT process. Note that the inductor $L_{B}$ for resonance was fabricated on chip for the ease of on-wafer measurements. In practical use, the on-chip input tuning inductor $L_{B}$ can be replaced by a bonding wire and hence, inherently, the proposed reconfigurable LNA only occupies a very small die area of $150 \mu \mathrm{m} \times 270 \mu \mathrm{m}$ excluding the measurement pads.

Normally, the MOS switch is off. As will be evident from the experimental results, this input matching technique can offer a very wideband-matching characteristic because only a small inductance inductor $L_{B}$ is needed [see Fig. 4(a)]. This is because the bandwidth of the LNA's $S_{11}$, i.e., the frequency range that satisfies $20 \log \left|S_{11}\right| \leq-10 \mathrm{~dB}$, is inversely proportional to the inductance of the inductor $L_{B}$ [10]. From (1)-(3), the equivalent input capacitance $C_{\mathrm{IN}}$ of the LNA in Fig. 4(a) can be expressed as a function of $C_{F}$ as follows:

$$
\begin{aligned}
C_{\mathrm{IN}} & \approx C_{B E 1}^{/}+C_{\mathrm{BC} 1-\mathrm{EQ}}^{\prime}\left(1+g_{m 1}^{\prime} R_{L}^{\prime}\right) \\
& \approx\left\{\begin{array}{l}
C_{B E 1}+C_{B C 1}\left(1+g_{m 1} R_{L}\right) \\
C_{B E 1}+\left(C_{B C 1}+C_{F}\right) \\
\times\left(1+g_{m 1} R_{L}\right)
\end{array}\right. \text { (switch-off) }
\end{aligned}
$$

Hence, $C_{\mathrm{IN}}$ increases as the MOS switch is turned on. The resonant frequency determined by $C_{\mathrm{IN}}$ and $L_{B}$ decreases accordingly and as a result, the resonant frequency for input matching also decreases. That is, the higher application band can be switched to a lower one by simply turning on the MOS switch. Note the reconfigurable LNA architecture, which is controlled by a switch and a capacitor, is also suitable for the CMOS technology. That is, though $g_{m}$ of MOSFET is smaller than that of the bipolar junction transistor (BJT), it can be compensated by adopting a parallel capacitor $\left(C_{F}\right)$ with a larger capacitance. In addition, equivalent input resistance $R_{\mathrm{IN}}$ can be adjusted to be nearly $50 \Omega$ by appropriate values of $R_{L}$,

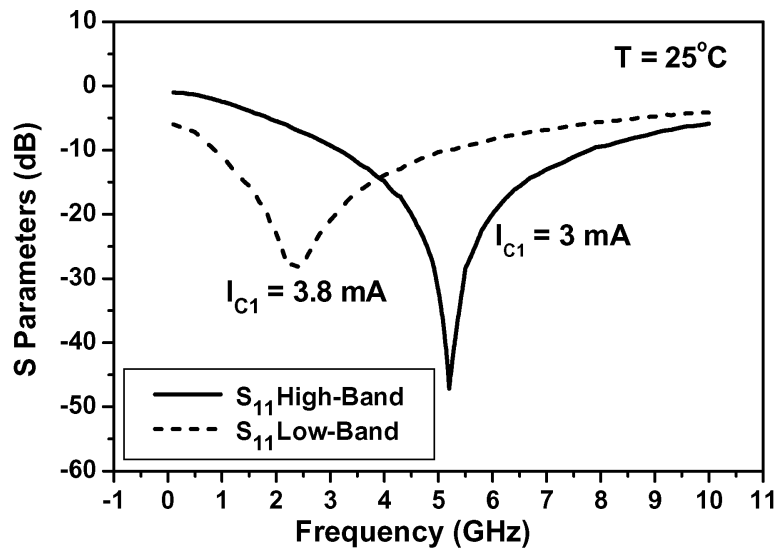

(a)

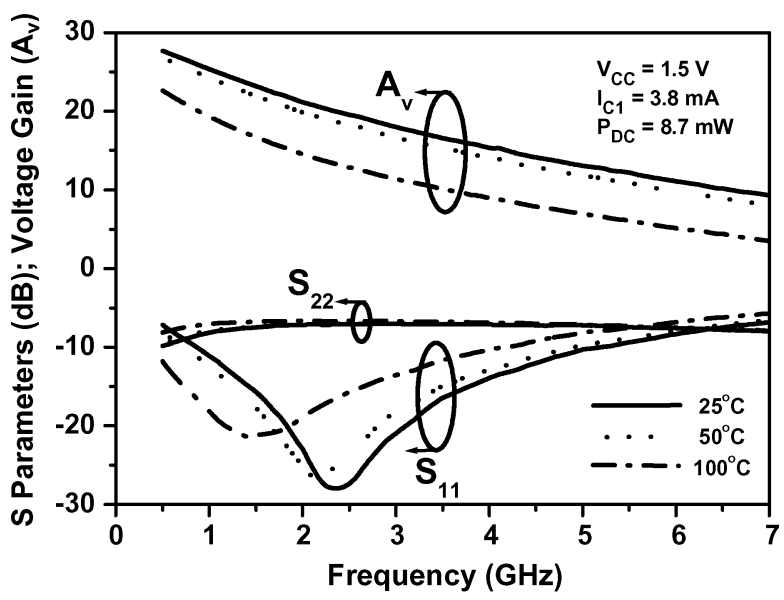

(b)

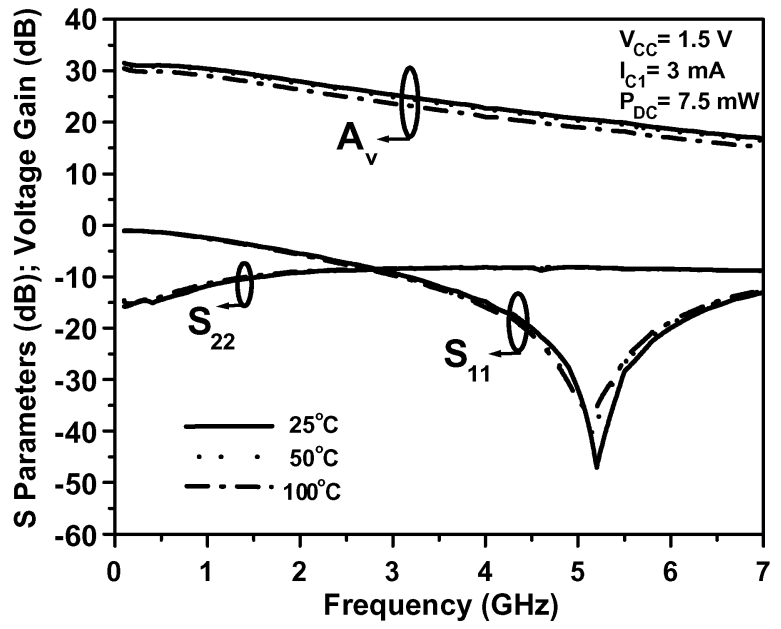

(c)

Fig. 5. (a) Measured scattering parameter $S_{11}$ at collector bias current (transistor $Q 1) I_{C 1}$ of 3 and $3.8 \mathrm{~mA}$ of the reconfigurable SiGe LNA achieved by switching bias current at room temperature. The measured voltage gain $\left(A_{v}\right)$ and scattering parameters $S_{11}$ and $S_{22}$ (b) at the 2.4-GHz mode, and (c) at the $5.2 / 5.7-\mathrm{GHz}$ mode of the reconfigurable $\mathrm{SiGe}$ LNA achieved by switching bias current at different temperatures.

$C_{L}, g_{m 1}$, and $C_{B C 1}$. Since the $g_{m}$ of MOSFET is smaller than that of BJT, from (2), (3), a smaller $C_{L}$ should be adopted for the CMOS version. 


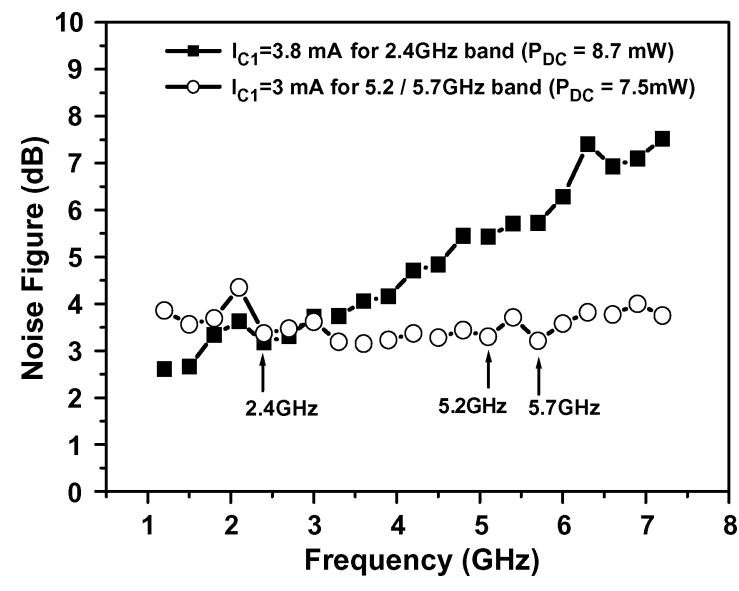

Fig. 6. Measured NFs at the bias current of $I_{C 1}=3.8 \mathrm{~mA}$ and $I_{C 1}=3 \mathrm{~mA}$ of the reconfigurable SiGe LNA achieved by switching bias currents.

\section{MEASUREMEnt RESUlts And Discussions}

\section{A. Reconfigurable SiGe LNA Achieved by Switching Bias Current}

The noise and scattering parameters of the reconfigurable SiGe LNA shown in Figs. 5 and 6 were measured on wafer using an automated NP5 measurement system from ATN Microwave Inc. Fig. 5(a) shows the measured scattering parameter $S_{11}$ when $Q 1$ transistor is biased with $I_{B 1 b}$ or $I_{B 1 a}$ current sources at room temperature. The $I_{B 1 b}$ base current resulted in a value of collector current $I_{C 1}$ of $3.8 \mathrm{~mA}$. When the base current of $Q 1$ is switched from $I_{B 1 b}$ to $I_{B 1 a}, I_{C 1}$ decreases from 3.8 to $3 \mathrm{~mA}$. Clearly, $5.2 / 5.7-\mathrm{GHz}$ application bands and $2.4-\mathrm{GHz}$ application band can be exchanged by simply switching the collector current between 3.0 and $3.8 \mathrm{~mA}$.

DC bias voltages and currents, and extracted ac small-signal parameters of HBTs $Q 1$ and $Q 2$ of the reconfigurable SiGe LNA when $V C C=1.5 \mathrm{~V}$ and $I_{C 1}=3.0 \mathrm{~mA}$ (i.e., corresponding to $5.2 / 5.7-\mathrm{GHz}$ band) are summarized in Table I. Based on the small-signal parameters listed in Table I and the circuit parameters shown in Fig. 3(a), the calculated input resistance $R_{\mathrm{IN}}$ by using (3) was equal to $49.21 \Omega$ at $5.2-\mathrm{GHz}$ when $I_{C 1}$ was biased at $3.0 \mathrm{~mA}$. In addition, the measured $R_{\mathrm{IN}}$ was $49.55 \Omega$ at $5.2 \mathrm{GHz}$ when $I_{C 1}$ was biased at $3.0 \mathrm{~mA}$. Clearly, the calculated result of $R_{\mathrm{IN}}$ was in good agreement with the measured result.

Fig. 5(b) shows the measured voltage gain $A_{v}$ and scattering parameters $S_{11}$ and $S_{22}$ of the LNA at various temperatures $\left(25,50\right.$, and $\left.100^{\circ} \mathrm{C}\right)$ when biased with collector current $I_{C 1}$ of $3.8 \mathrm{~mA}$. Supply voltage $V_{\mathrm{CC}}$ was equal to $1.5 \mathrm{~V}$. Voltage gain $A_{v}$ was $19.8 \mathrm{~dB}$ at $2.4 \mathrm{GHz}$. Since this LNA is intended for integrated front-end circuits, the voltage gain $\left(A_{V}\right)$ instead of $S_{21}$ is reported here [5]. The input return loss $S_{11}$ was below $-27.6 \mathrm{~dB}$ from 2.4 to $2.5 \mathrm{GHz}$. $S_{22}$ showed a very broadband matching. Note, however, for low intermediate frequency (IF) or zero-IF applications, $S_{22}$ does not have to be matched to $50 \Omega$. When $I_{C 1}$ was reduced to $3 \mathrm{~mA}$ by switching the base current of $Q 1$ from $I_{B 1 B}$ to $I_{B 1 a}, C_{\mathrm{IN}}$ decreased, and hence, the frequency band for input matching was switched to higher frequency bands as shown in Fig. 5(c). Now $S_{11}$ was below $-34.2 \mathrm{~dB}$ from 5.1 to $5.4 \mathrm{GHz}$ and below $-21 \mathrm{~dB}$ from 5.7 to $5.9 \mathrm{GHz}$. Voltage
TABLE I

DC Bias Voltages AND CURRENTS, AND EXTRACTEd AC SMALl-Signal PARAMETERS OF HBTS $Q 1$ AND $Q 2$ OF THE RECONFIGURABLE SiGe LNA (ACHIEVED BY SWITCHING BIAS CURRENTS) WHEN $V_{\mathrm{CC}}=1.5 \mathrm{~V}$ AND $I_{C 1}=3.0 \mathrm{~mA}$ (I.E., CORRESPONDING TO 5.2/5.7-GHz BAND)

\begin{tabular}{|c|c|c|}
\cline { 2 - 3 } \multicolumn{1}{c|}{} & \multicolumn{2}{c|}{$\mathrm{P}_{\mathrm{DC}}=7.5 \mathrm{~mW}$} \\
\multicolumn{1}{c|}{} & $\mathrm{V}_{\text {BIAS }}=0.956 \mathrm{~V}, \mathrm{~V}_{\mathrm{CC}}=1.5 \mathrm{~V}$ \\
\hline & $\mathrm{Q}_{1}$ & $\mathrm{Q}_{2}$ \\
\hline $\mathrm{I}_{\mathrm{B}}(\mu \mathrm{A})$ & 16.6 & 11.09 \\
\hline $\mathrm{I}_{\mathrm{C}}(\mathrm{mA})$ & 3 & 1.97 \\
\hline $\mathrm{r}_{\mathrm{b}}(\Omega)$ & 15 & 15 \\
\hline $\mathbf{r}_{\mathrm{c}}(\Omega)$ & 3.2 & 3.2 \\
\hline $\mathrm{r}_{\mathrm{e}}(\Omega)$ & 2 & 2 \\
\hline $\mathrm{g}_{\mathrm{m}}(\mathrm{mS})$ & 92 & 60.5 \\
\hline $\mathrm{R}_{\mathrm{be}}(\mathrm{k} \Omega)$ & 2.5 & 2.5 \\
\hline $\mathrm{r}_{0}(\mathrm{k} \Omega)$ & 4.8 & 4.8 \\
\hline $\mathrm{C}_{\mathrm{bc}}(\mathrm{fF})$ & 72 & 61.5 \\
\hline $\mathrm{C}_{\mathrm{be}}(\mathrm{fF})$ & 285 & 259 \\
\hline
\end{tabular}

gain $A_{v}$ was 20.4 and $19.3 \mathrm{~dB}$ at 5.2 and $5.7 \mathrm{GHz}$, respectively. The noise performance is shown in Fig. 6. Noise figures (NFs) of 3.18, 3.42, and $3.21 \mathrm{~dB}$ were obtained at 2.4, 5.2, and $5.7 \mathrm{GHz}$, respectively. The power consumptions were only 8.7 and $7.5 \mathrm{~mW}$ for 2.4 and $5.2 / 5.7-\mathrm{GHz}$ bands, respectively. From the experimental results, it is clear that a miniaturized fully monolithic $2.4 / 5.2 / 5.7-\mathrm{GHz}$ multiband LNA with low power consumption for WLAN applications was realized by a simple bias switching technique.

The characteristics of $S$-parameters at temperatures other than room temperature are also shown in Fig. 5(b) and (c). From Fig. 5(b), it is clear that the resonant frequency of $S_{11}$ at room temperature with $I_{C 1}=3.8 \mathrm{~mA}$ shifted to lower frequencies of 2.1 and $1.4 \mathrm{GHz}$ at $50^{\circ} \mathrm{C}$ and $100^{\circ} \mathrm{C}$, respectively. Nevertheless, even at $100{ }^{\circ} \mathrm{C}, S_{11}$ was still below $-15.6 \mathrm{~dB}$ from 2.4 to $2.5 \mathrm{GHz}$. From Fig. 5(c), the resonant frequency of $S_{11}$ at room temperature with $I_{C 1}=3 \mathrm{~mA}$ shifted to a lower frequency of $5.1 \mathrm{GHz}$ both at $50^{\circ} \mathrm{C}$ and $100{ }^{\circ} \mathrm{C}$. $S_{11}$ was still below $-34 \mathrm{~dB}$ from 5.15 to $5.35 \mathrm{GHz}$ and below $-21 \mathrm{~dB}$ from 5.725 to $5.825 \mathrm{GHz}$.

Power gain of an LNA depends on both $S_{11}$ and $A_{v}$ [11]. According to the measurement results in Fig. 5, though the switching (bias current) input matching point method does not affect $A_{v}$ much, it makes sure the LNA exhibits good $S_{11}$ performances, i.e., good power gain performances, in all the bands of interest.

An expression which is often used to characterize the stability of an LNA is the Stern stability factor ( $K$-factor), defined as

$$
K=\frac{1+|\Delta|^{2}-\left|S_{11}\right|^{2}-\left|S_{22}\right|^{2}}{2\left|S_{21}\right|\left|S_{12}\right|}
$$

where $\Delta=S_{11} S_{22}-S_{12} S_{21}$. If $K>1$ and $|\Delta|<1$, then the circuit is unconditionally stable [12]. In addition, it has been shown that $\mu>1$ (or $\mu^{\prime}>1$ ) alone is necessary and sufficient for a circuit to be unconditionally stable [13], where

$$
\mu \equiv \frac{1-\left|S_{11}\right|^{2}}{\left|S_{22}-S_{11}^{*} \Delta\right|+\left|S_{21}\right|\left|S_{12}\right|}
$$




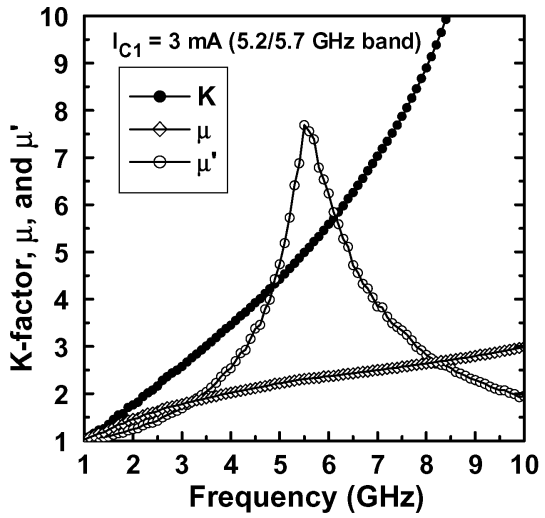

(a)

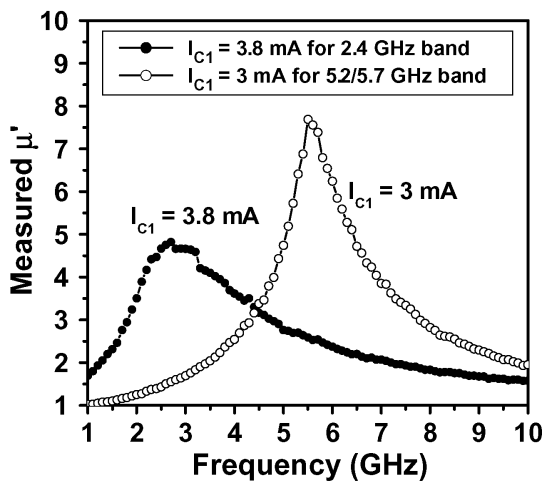

(b)

Fig. 7. Measured (a) $K$-factor $\mu$ and $\mu^{\prime}$ versus frequency characteristics at the higher band $\left(5.2 / 5.7 \mathrm{GHz}\right.$ ). (b) $\mu^{\prime}$ versus frequency characteristics at both the higher band $(5.2 / 5.7 \mathrm{GHz})$ and the lower band $(2.4 \mathrm{GHz})$ of the reconfigurable SiGe LNA achieved by switching bias currents.

$$
\mu^{\prime} \equiv \frac{1-\left|S_{22}\right|^{2}}{\left|S_{11}-S_{22}^{*} \Delta\right|+\left|S_{21}\right|\left|S_{12}\right|} .
$$

Fig. 7(a) shows the measured $K$-factor, $\mu$, and $\mu^{\prime}$ at collector bias current (transistor $Q 1) I_{C 1}$ of $3 \mathrm{~mA}$ of the reconfigurable SiGe LNA achieved by switching bias current at room temperature. Fig. 7(b) shows the measured $\mu^{\prime}$ of the LNA at $I_{C 1}$ of 3 and $3.8 \mathrm{~mA}$. Clearly, for both the higher band $(5.2 / 5.7 \mathrm{GHz})$ and the lower band $(2.4 \mathrm{GHz})$, the LNA is unconditionally stable from 1 to $10 \mathrm{GHz}$. For both the higher band and the lower band, the frequency corresponding to the maximum $\mu^{\prime}$ is close to the frequency corresponding to the minimum $S_{11}$ (i.e., 2.4 and $5.2 \mathrm{GHz}$ ) in Fig. 5(a). This is because $\mu^{\prime}$ is roughly inversely proportional to $S_{11}$ [see (8)]. In addition, at frequencies close to the minimum $S_{11}$, both $K$-factor and $\mu$ increase with the increase of frequency mainly because $A_{v}$ ( or $S_{21}$ ) monotonously decreases with the increase of frequency [see Fig. (5b) and (c)]. The measured $K$-factor, $\mu$, and $\mu^{\prime}$ versus frequency characteristics of the 5-GHz-band CMOS LNA in [10] were shown in Fig. 8 for comparison. Clearly, for a narrowband CMOS LNA (with good tuning range), the phenomenon that the frequency corresponding to the maximum $\mu^{\prime}$ is close to the frequency corresponding to the minimum $S_{11}$ also exists. However, the frequency corresponding to the maximum $A_{v}$ (or $S_{21}$ ) is close to the frequency corresponding to the minimum $K$-factor and $\mu$ which is different from the LNAs studied in this work. This

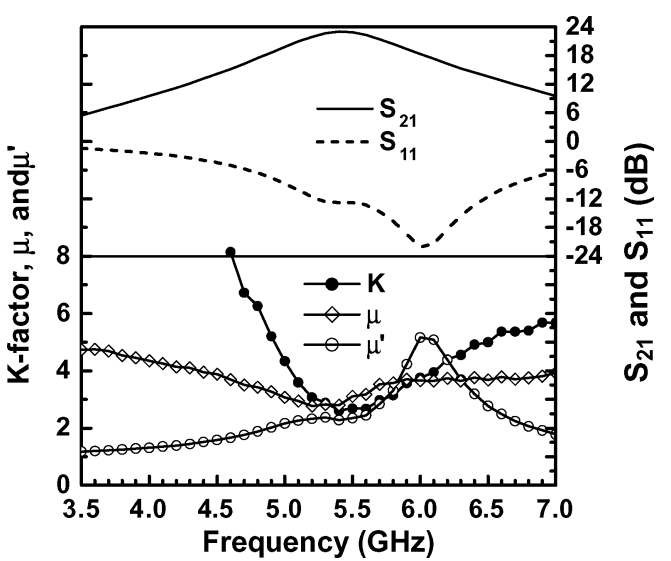

Fig. 8. Measured $K$-factor, $\mu$, and $\mu^{\prime}$ versus frequency characteristics of the 5-GHz-band CMOS LNA in [10].

TABLE II

SUMMARY OF MEASURED RESULTS OF THE RECONFIGURABLE SiGe LNA ACHIEVED BY SWITCHING BIAS CURRENTS

\begin{tabular}{|c|c|c|c|c|c|c|c|}
\hline $\begin{array}{c}\mathrm{V}_{\mathrm{CC}} \\
(\mathrm{V})\end{array}$ & $\begin{array}{c}\mathrm{I}_{\mathrm{C} 1} \\
(\mathrm{~mA})\end{array}$ & $\begin{array}{c}\mathrm{F}_{\mathrm{C}} \\
(\mathrm{GHz})\end{array}$ & $\begin{array}{c}\mathrm{NF} \\
(\mathrm{dB})\end{array}$ & $\begin{array}{c}\mathrm{P}_{\mathrm{DC}} \\
(\mathrm{mW})\end{array}$ & $\begin{array}{c}\mathrm{A}_{\mathrm{V}} \\
(\mathrm{dB})\end{array}$ & $\begin{array}{c}\mathrm{S}_{11} \\
(\mathrm{~dB})\end{array}$ & $\begin{array}{c}\mathrm{S}_{12} \\
(\mathrm{~dB})\end{array}$ \\
\hline 1.5 & 3.8 & 2.4 & 3.18 & 8.7 & 19.8 & -27.6 & -38 \\
\hline 1.5 & 3 & 5.2 & 3.42 & 7.5 & 20.4 & -47.1 & -38.1 \\
\hline 1.5 & 3 & 5.7 & 3.21 & 7.5 & 20.3 & -24.6 & -38.6 \\
\hline 2 & 5.1 & 2.4 & 1.72 & 17.2 & 26.2 & -17.2 & -42.3 \\
\hline 2 & 3 & 5.2 & 2.79 & 13 & 24.4 & -18 & -37.6 \\
\hline 2 & 3 & 5.7 & 2.73 & 13 & 23.4 & -17.5 & -36.9 \\
\hline
\end{tabular}

is reasonable because $K$-factor is inversely proportional to $S_{21}$ [see (6)] and $\mu$ is roughly inversely proportional to $S_{21}$ [see (7)].

$S$-parameters and NFs at $V_{\mathrm{CC}}=2 \mathrm{~V}$ under room temperature were also measured and summarized in Table II. To our knowledge, the NF (2.73 dB) achieved is the state-of-the-art result among all C-band silicon-bipolar based LNAs with fully on-chip input matching network. The measured input third-order intercept point $\left(\mathrm{IIP}_{3}\right)$ and input 1-dB compression point $\left.P_{1 \mathrm{~dB}}\right)$ at $2.4 \mathrm{GHz}$ of the reconfigurable SiGe LNA achieved by switching bias currents is shown in Fig. 9. $\mathrm{IIP}_{3}$ of $-30.5 \mathrm{dBm}$ and $P_{1 \mathrm{~dB}}$ of $-23 \mathrm{dBm}$ were obtained for the $\mathrm{SiGe}$ LNA. The low or mediocre linearity of the reconfigurable LNA is mainly because the dc bias point of the transistor $Q 1$ is close to the saturation region (i.e., $V_{\mathrm{CE}}$ is not high enough) due to the low supply voltage $\left(V_{\mathrm{DD}}\right)$ of $1.5 \mathrm{~V}$ and high de voltage drop of the bias resistor $R 1$ (about $1.14 \mathrm{~V}$ ). The linearity of the LNA is expected to be largely improved if the bias points of the transistors in the LNA are designed in the vicinity of half $V_{\mathrm{DD}}$. Table II is a summary of the measured results for the reconfigurable SiGe LNA achieved by switching bias currents.

\section{B. Reconfigurable SiGe LNA Controlled by a Switch and a Capacitor}

The measured voltage gain $A_{v}$ and scattering parameter $S_{11}$ of the reconfigurable SiGe LNA biased with supply voltage of $2 \mathrm{~V}$ (total current of $7.96 \mathrm{~mA}$ ) are shown in Fig. 10. Switch 


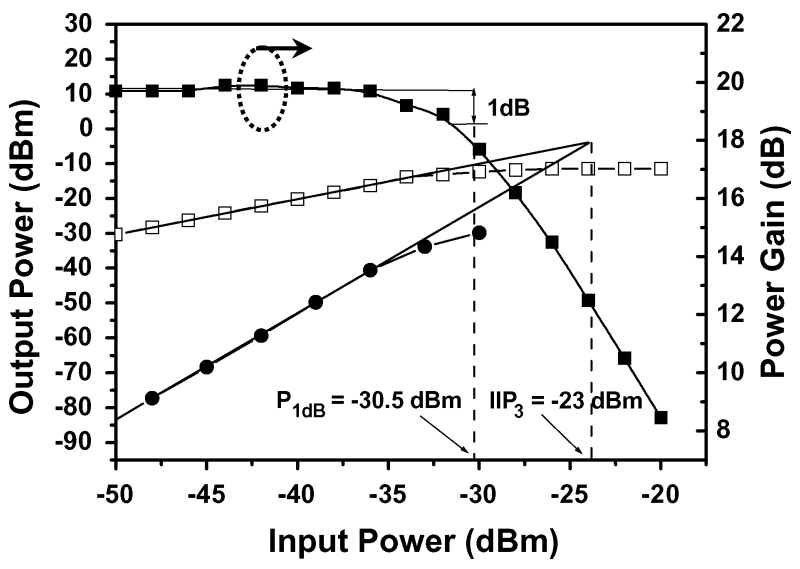

Fig. 9. Measured $\operatorname{IIP}_{3}$ and $P_{1 \mathrm{~dB}}$ at $2.4 \mathrm{GHz}$ of the reconfigurable SiGe LNA achieved by switching bias currents.

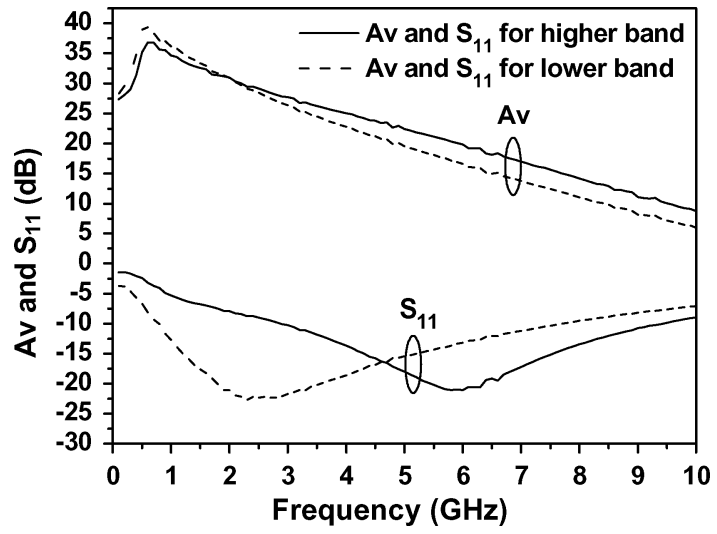

Fig. 10. Measured voltage gain $\left(A_{v}\right)$ and scattering parameters $S_{11}$ of the reconfigurable SiGe LNA with variable shunt-shunt feedback capacitance controlled by a switch and a capacitor.

control voltage $\left(V_{\text {ctrl }}\right)$ was equal to 2 and $0 \mathrm{~V}$ for lower band $(2.4 \mathrm{GHz})$ and higher band $(4.9 \sim 5.85 \mathrm{GHz})$, respectively. The input return loss $S_{11}$ was below $-10 \mathrm{~dB}$ from 2.8 to $9.5 \mathrm{GHz}$. The voltage gains at important application bands were 22.9, 21.9 , and $20.7 \mathrm{~dB}$ at $4.9,5.2$, and $5.7 \mathrm{GHz}$, respectively. When the MOS switch was turned on, $S_{11}$ was below $-10 \mathrm{~dB}$ from 0.8 to $7.7 \mathrm{GHz}$. Voltage gain was $28.8 \mathrm{~dB}$ at $2.4 \mathrm{GHz}$.

Fig. 11(a) shows the measured $K$-factor $\mu$, and $\mu^{\prime}$ at the higher band (i.e., switch off) of the reconfigurable SiGe LNA (controlled by a switch and a capacitor) at $V_{\mathrm{CC}}$ of $2 \mathrm{~V}$. Fig. 11(b) shows the measured $\mu^{\prime}$ at both the higher band and the lower band (i.e., switch on). As can be seen, for both the higher band and the lower band, the LNA is unconditionally stable from $1 \mathrm{GHz}$ to $10 \mathrm{GHz}$ for both $V_{\mathrm{CC}}=1.5 \mathrm{~V}$ and $2.0 \mathrm{~V}$. For both the higher band and the lower band, the frequency corresponding to the maximum $\mu^{\prime}$ is close to the frequency corresponding to the minimum $S_{11}$ (i.e., 2.3 and $6 \mathrm{GHz}$ ) in Fig. 10. The trend is the same with both the reconfigurable SiGe LNA achieved by switching bias currents [see Fig. 7(a)] and the 5-GHz-band CMOS LNA (see Fig. 8). In addition, at frequencies close to the minimum $S_{11}$, both $K$-factor and $\mu$ increase with the increase of frequency mainly because $A_{v}$ monotonously decreases with the increase of frequency (see Fig. 10). The trend is the same with the reconfigurable SiGe LNA achieved by switching bias currents see Fig. 7(a).

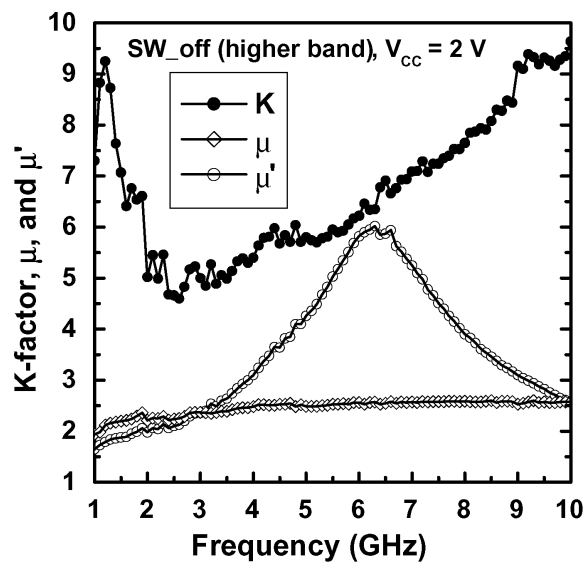

(a)

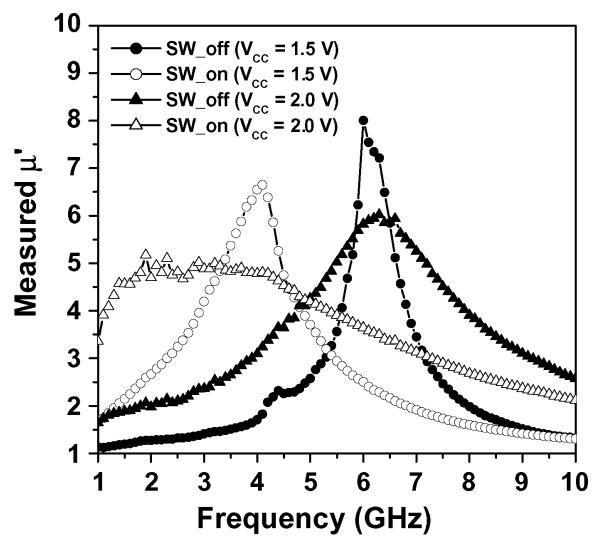

(b)

Fig. 11. Measured (a) $K$-factor, $\mu$, and $\mu^{\prime}$ versus frequency characteristics at the higher band (i.e switch off), and (b) $\mu^{\prime}$ versus frequency characteristics at both the higher band (i.e., switch off) and the lower band (i.e., switch on) of the reconfigurable SiGe LNA with variable shunt-shunt feedback capacitance controlled by a switch and a capacitor.

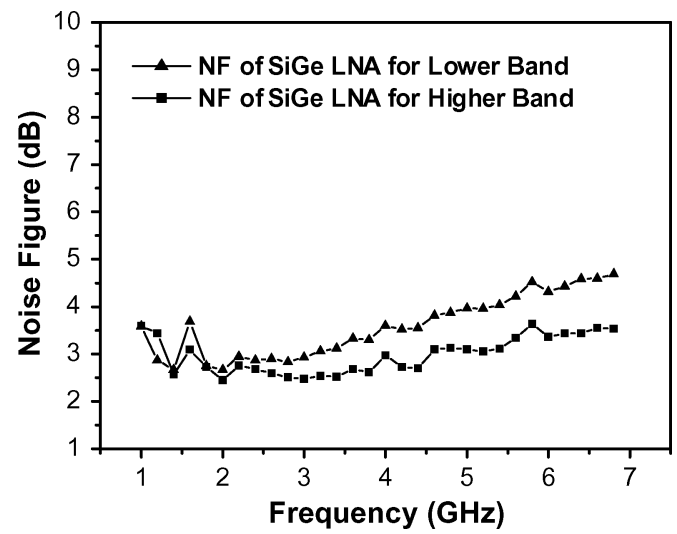

Fig. 12. Measured NFs of the reconfigurable SiGe LNA with variable shunt-shunt feedback capacitance controlled by a switch and a capacitor.

The measured noise performance of the reconfigurable $\mathrm{SiGe}$ LNA is shown in Fig. 12. NFs of 2.8, 3.1, 3.0, and $3.5 \mathrm{~dB}$ were obtained at 2.4, 4.9, 5.2 , and $5.75 \mathrm{GHz}$, respectively. Note that the $\mathrm{NF}(3.5 \mathrm{~dB})$ at $5.85 \mathrm{GHz}$ of our SiGe LNA with on-chip base inductor was better than that $(3.8 \mathrm{~dB})$ of the traditional $\mathrm{SiGe}$ LNA with an off-chip bond-wire base inductor and an on-chip emitter degenerative inductor [13]. It is expected that the noise 


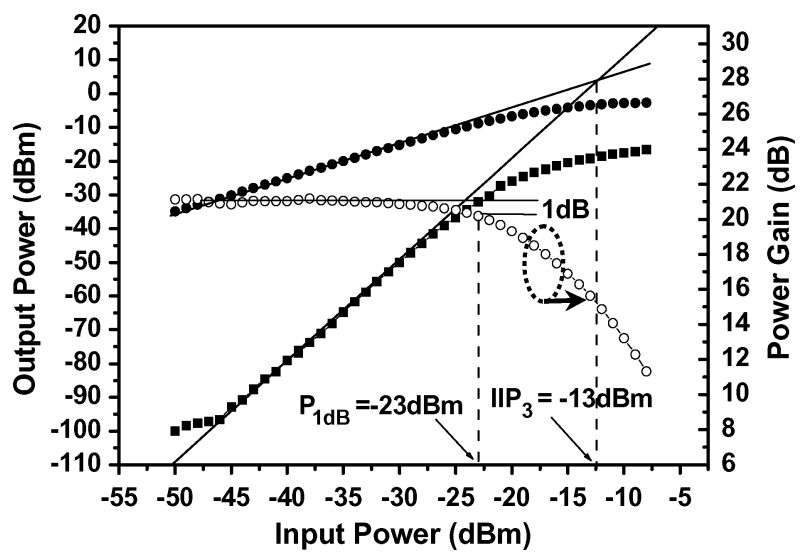

Fig. 13. Measured $\operatorname{IIP}_{3}$ and $P_{1}$ dB at $5.2 \mathrm{GHz}$ of the reconfigurable SiGe LNA with variable shunt-shunt feedback capacitance controlled by a switch and a capacitor.

TABLE III

SumMary of PERFormances OF RECONFIGURABLE SiGe LNA With VARIABLE SHUNT-SHUNT FEEDBACK CAPACITANCE CONTROLLED BY A SWITCH AND A CAPACITOR

\begin{tabular}{|c|c|c|c|c|}
\hline & \multicolumn{2}{|c|}{$\begin{array}{l}\text { SiGe LNA } \\
\text { @ } 2.4 \mathrm{GHz}\end{array}$} & \multicolumn{2}{|c|}{$\begin{array}{c}\text { SiGe LNA } \\
@ 4.9 \sim 5.85 \mathrm{GHz}\end{array}$} \\
\hline $\mathrm{V}_{\mathrm{CC}}(\mathrm{V})$ & 2 & 1.5 & 2 & 1.5 \\
\hline $\mathrm{S}_{11}(\mathrm{~dB})$ & -22.2 & -13.1 & $-17.5 \sim-21$ & $-9.8 \sim-18.6$ \\
\hline$A_{v}(d B)$ & 28.8 & 15.8 & $22.9 \sim 20.3$ & $17.2 \sim 15.9$ \\
\hline $\mathrm{S}_{12}(\mathrm{~dB})$ & -42.2 & -37.5 & $-38.6 \sim-36.8$ & $-39 \sim-40.2$ \\
\hline $\mathrm{NF}(\mathrm{dB})$ & 2.87 & 3.13 & $3.1 \sim 3.64$ & NA \\
\hline $\mathrm{P}_{1 \mathrm{~dB}}(\mathrm{dBm})$ & -28 & -13 & $\begin{array}{c}-23 \\
(@ 5.2 \mathrm{GHz})\end{array}$ & NA \\
\hline $\mathrm{IIP}_{3}(\mathrm{dBm})$ & -18 & -6 & $\begin{array}{c}-13 \\
(@ 5.2 \mathrm{GHz})\end{array}$ & NA \\
\hline
\end{tabular}

and the gain $\left(S_{21}\right)$ performances of our reconfigurable LNA can be further enhanced if an off-chip bond-wire base inductor is used, due to its lower parasitics related loss than that of the on-chip inductors.

The measured $\mathrm{IIP}_{3}$ and $P_{1 \mathrm{~dB}}$ at $5.2 \mathrm{GHz}$ of the reconfigurable $\mathrm{SiGe}$ LNA is shown in Fig. 13. $\mathrm{IIP}_{3}$ of $-13 \mathrm{dBm}$ and $P_{1 \mathrm{~dB}}$ of $-23 \mathrm{dBm}$ were obtained for the $\mathrm{SiGe}$ LNA. The performances of the reconfigurable SiGe LNA controlled by a switch and a capacitor are summarized in Table III. Note that even at a low voltage of $1.5 \mathrm{~V}$, the LNA still functions well.

\section{CONCLUSION}

Two miniaturized fully monolithic reconfigurable $\mathrm{SiGe}$ LNAs for 2.4/4.9/5.2/5.7 GHz WLAN are demonstrated. Input matching is achieved by the new shunt-shunt feedback capacitance technique instead of traditional series-series inductor feedback technique. Two approaches are proposed to reconfigure the LNAs. One approach is to switch between different bias currents while the other is to use a switch and a capacitor. Both reconfigurable LNA consume very small $(355 \mu \mathrm{m} \times 155 \mu \mathrm{m}$ and $150 \mu \mathrm{m} \times 270 \mu \mathrm{m})$ die area excluding the measurement pads. The new technique also shows a very wide input matching bandwidth.

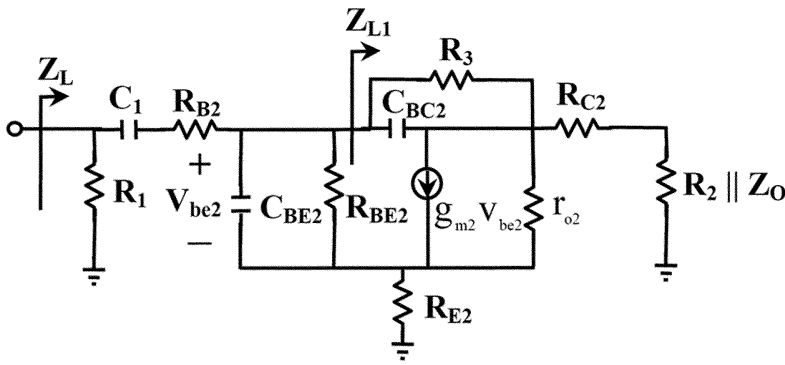

(a)

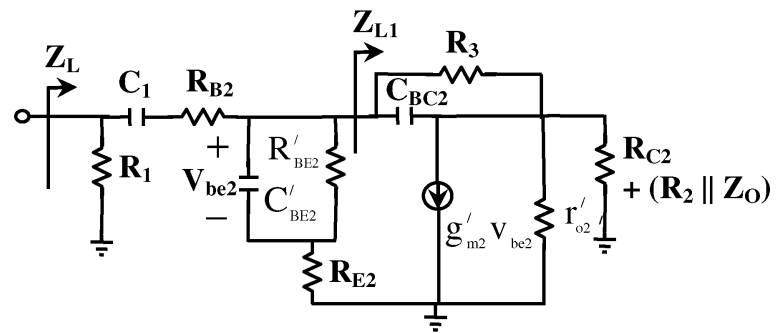

$\mathrm{g}_{\mathrm{m} 2}^{\prime}=\mathrm{g}_{\mathrm{m} 2} /\left(1+\mathrm{g}_{\mathrm{m} 2} \mathrm{R}_{\mathrm{E} 2}\right)$
$\mathrm{C}_{\mathrm{BE} 2}^{\prime}=\mathrm{C}_{\mathrm{BE} 2} /\left(1+\mathrm{g}_{\mathrm{m} 2} \mathrm{R}_{\mathrm{E} 2}\right)$
$\mathrm{R}_{\mathrm{BE} 2}^{\prime}=\mathrm{R}_{\mathrm{BE} 2} \cdot\left(1+\mathrm{g}_{\mathrm{m} 2} \mathrm{R}_{\mathrm{E} 2}\right) !$
$\mathrm{r}_{\mathrm{o} 2}^{\prime}=\mathrm{r}_{\mathrm{o} 2} \cdot\left(1+\mathrm{g}_{\mathrm{m} 2} \mathrm{R}_{\mathrm{E} 2}\right)$
$\mathrm{i} \cdot \cdot-\cdot \cdot-\cdot]$

(b)

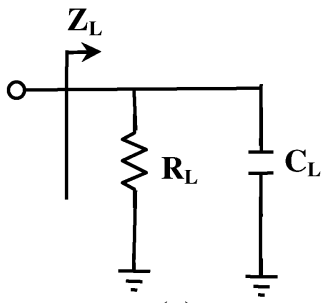

(c)

Fig. 14. (a) Small-signal equivalent circuit to find the load impedance $Z_{L}$ seen at the collector terminal of transistor $Q 1$ of the reconfigurable SiGe LNAs shown in Figs. 3(a) and 4(a). (b)-(c) Detailed steps to simplify the equivalent circuit shown in Fig. (14a) to find the load impedance $Z_{L}$.

\section{APPENDIX}

\section{A. Expression of Load Impedance $Z_{L}$}

Fig. 14(a) shows the small-signal equivalent circuit to find the necessary load impedance $Z_{L}$ for matching seen at the collector terminal of transistor $Q 1$ of the reconfigurable SiGe LNA shown in Figs. 3(a) and 4(a). The circuit of Fig. 14(a) can be transformed into that of Fig. 14(b) with some necessary circuit element modifications [8], which are also shown in Fig. 14(b). From Fig. 14(b), the impedance $Z_{L 1}$ can be expressed as follows:

$$
\begin{aligned}
Z_{L 1} & =\frac{\left(R_{3} \| \frac{1}{s C_{B C 2}}\right)+R_{L 2}}{1+g_{m 2}^{\prime \prime} R_{L 2}} \\
& =\frac{R_{3}}{1+g_{m 2}^{\prime \prime} R_{L 2}} \cdot \frac{1}{1+s C_{B C 2} R_{3}}+\frac{R_{L 2}}{1+g_{m 2}^{\prime \prime} R_{L 2}}
\end{aligned}
$$




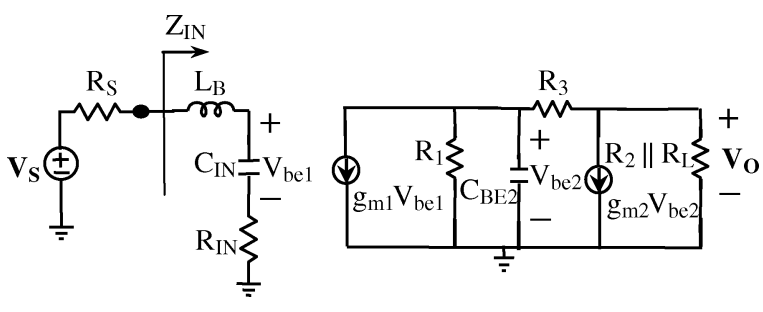

Fig. 15. Simplified small-signal equivalent circuit of the reconfigurable $\mathrm{SiGe}$ LNA in Fig. 3(a) for the purpose of calculating the LNA's $A_{V}$.

where $g_{m 2}^{\prime \prime}=\left(g_{m 2}^{\prime} \cdot R_{B E 2}^{\prime}\right) /\left(R_{B E 2}^{\prime}+R_{E 2}+s C_{B E 2}^{\prime}\right.$ $\left.R_{B E 2}^{\prime} R_{E 2}\right), R_{B E 2}^{\prime}=R_{B E 2}\left(1+g_{m 2} R_{E 2}\right), C_{B E 2}^{\prime}=$ $C_{B E 2} /\left(1+g_{m 2} R_{E 2}\right), g_{m 2}^{\prime}=g_{m 2} /\left(1+g_{m 2} R_{E 2}\right)$, and $R_{L 2}$ is the parallel combination of $R_{C 2}+\left(R_{2} \| Z_{\mathrm{O}}\right)$ and $r_{\mathrm{o} 2}^{\prime}=r_{\mathrm{o} 2}\left(1+g_{m 2} R_{E 2}\right) . Z_{L 1}$ can be simplified as a parallel $R C$ circuit as follows:

$$
\begin{aligned}
Z_{L 1} & \approx \frac{R_{3}}{1+g_{m 2}^{\prime} R_{L 2}} \cdot \frac{1}{1+s C_{B C 2}}+\frac{R_{3}+R_{L 2}}{1+g_{m 2}^{\prime} R_{L 2}} \\
\approx & \left(\frac{R_{3}+R_{L 2}}{1+g_{m 2}^{\prime} R_{L 2}}\right) \| \\
& \left(1 /\left[s C_{B C 2}\left(\frac{R_{3}}{R_{L 2}+R_{3}}\right)^{2}\left(1+g_{m 2}^{\prime} R_{L 2}\right)\right]\right) \\
& \left(R_{Q 2}\right) \|\left(\frac{1}{s C_{Q 2}}\right) .
\end{aligned}
$$

In (10), we assume that $\left(R_{L 2}+R_{3}\right) /\left(1+g_{m 2}^{\prime} R_{L 2}\right) \gg$ $\left(s C_{B C 2} R_{3} R_{L 2}\right) /\left(1+g_{m 2}^{\prime} R_{L 2}\right)$ and $R_{B E 2}^{\prime} \gg\left(R_{E 2}+\right.$ $s C_{B E 2}^{\prime} R_{B E 2}^{\prime} R_{E 2}$ ), which is usually the case. Once the $Z_{L 1}$ is known, the impedance $Z_{L}$ can be simplified as a parallel $R C$ circuit as follows:

$$
\begin{aligned}
Z_{L} \approx & \left(R_{1} \| \frac{\left[R\left(C_{1}+C\right)+R_{B 2} C_{1}\right]}{C_{1}}\right) \\
& \|\left(\frac{1}{s C C_{1} R /\left[R\left(C+C_{1}\right)+R_{B 2} C_{1}\right]}\right) \\
& \equiv\left(R_{L}\right) \|\left(\frac{1}{s C_{L}}\right)
\end{aligned}
$$

where $C=C_{B E 2}^{\prime}+C_{Q 2}$ and $R=R_{B E 2}^{\prime} \| R_{Q 2}$. The desired values of $C_{L}$ and $R_{L}$ can be obtained by appropriate values of $R_{1}, R_{2}, R_{3}$, transconductance $g_{m 2}$, and base-collector capacitance $C_{B C 2}$, etc.

\section{B. Expression of $A_{v}$ of the Reconfigurable SiGe LNA Achieved by Switching Bias Current}

Fig. 15 shows the simplified small-signal model of the reconfigurable SiGe LNA in Fig. 3(a) for the purpose of calculating the LNA's voltage gain $A_{v}$ (and $S_{21}$ ). $R_{S}$ (source resistance of the voltage source) and $R_{L}$ (load resistance), which are normally equal to $50 \Omega$, are connected to the input and the output port, respectively, of the LNA [8], [15]. The transfer function of $A_{v}\left(=V_{\mathrm{O}} / V_{S}\right)$ can be derived as follows:

$$
\begin{aligned}
A_{V}= & \frac{V_{\mathrm{O}}}{V_{S}} \\
\approx & \frac{\frac{1}{s C_{\mathrm{IN}}}}{R_{S}+s L_{B}+\frac{1}{s C_{\mathrm{IN}}}+R_{\mathrm{IN}}} \cdot g_{m 1} \\
& \cdot\left(R_{1} \| \frac{1}{s C_{B E 2}}\right) \cdot\left(g_{m 2}-\frac{1}{R_{3}}\right) \cdot\left(R_{3}\left\|R_{2}\right\| R_{L}\right) \\
\approx & \frac{g_{m 1}}{s^{2} L_{B} C_{\mathrm{IN}}+1+s\left(R_{S}+R_{\mathrm{IN}}\right) C_{\mathrm{IN}}} \cdot\left(R_{1} \| \frac{1}{s C_{B E 2}}\right) \\
& \cdot\left(g_{m 2}-\frac{1}{R_{3}}\right) \cdot\left(R_{3}\left\|R_{2}\right\| R_{L}\right) \\
\approx & \frac{g_{m 1}}{s^{2} L_{B} C_{\mathrm{IN}}+1+2 s C_{\mathrm{IN}} R_{\mathrm{IN}}} \cdot\left(R_{1} \| \frac{1}{s C_{B E 2}}\right) \\
& \cdot\left(g_{m 2}-\frac{1}{R_{3}}\right) \cdot\left(R_{3}\left\|R_{2}\right\| R_{L}\right) \\
\equiv & G_{M 11} \cdot Z_{\mathrm{RFB}}
\end{aligned}
$$

in which

$$
G_{M 11}=\frac{g_{m 1}}{s^{2} L_{B} C_{\mathrm{IN}}+1+2 s C_{\mathrm{IN}} R_{\mathrm{IN}}}
$$

and

$$
Z_{\mathrm{RFB}}=\left(R_{1} \| \frac{1}{s C_{B E 2}}\right) \cdot\left(g_{m 2}-\frac{1}{R_{3}}\right) \cdot\left(R_{3}\left\|R_{2}\right\| R_{L}\right)
$$

are the transconductance gain of the first stage and the trans-impedance gain of the second stage, respectively. Apparently, $G_{M 11}$ is equivalent to the transfer function of a second-order low- $Q$ low-pass $R L C$ circuit [16]. For example, $Q=\sqrt{L_{B} / C_{\mathrm{IN}}} /\left(2 R_{\mathrm{IN}}\right) \approx 0.209$ and 0.454 (i.e., over-damped response), respectively, if $f_{0}\left(=\omega_{0} / 2 \pi\right)$ is specified to be 2.4 and $5.2 \mathrm{GHz}$.

According to (13), for frequencies not too far from the minimum $S_{11}$ (i.e., $s^{2} L_{B} C_{\mathrm{IN}}+1 \sim 0$ ), $G_{M 11}$ is roughly proportional to $1 / \mathrm{s}$. Because the pole contributed by $C_{B E 2}$ is about $2.05 \mathrm{GHz}$, which is smaller than $2.4 \mathrm{GHz}$, the calculated $A_{v}$ exhibits about $-40 \mathrm{~dB} /$ decade characteristics in the frequency range of interest for both the 2.4 and 5.2/5.7 GHz modes. Fig. 16 shows the calculated $A_{v}$ of the $5.2 / 5.7 \mathrm{GHz}$ mode. Its trend is consistent with the measured characteristics in Fig. 5(c). This explains why in Fig. 5(b) and (c) the $A_{v}$ curves do not reflect the trend of $S_{11}$ at all though the trend of $S_{22}$ is roughly flat. In other words, for a wideband LNA, the trend of $A_{v}$ is mainly determined by the positions of its poles and zeros. This is in contrast to the narrowband LNAs [10], [17], the maximum $A_{v}$ of which is roughly corresponding to the minimum $S_{11}$ (and/or $S_{22}$ ).

Besides, for the reconfigurable LNA in Fig. 3(a), the reason why good tuning range of $A_{v}$ (by varying the bias current of $I_{B 1}$ or $I_{C 1}$ ) can not be reached [see Fig. 5(b) and (c)] is mainly because both the equivalent input capacitance $C_{\mathrm{IN}}$ and the transconductance $g_{m 1}$ of the input transistor increase with the increase of bias current. To be more specific, for frequencies not too far from the minimum $S_{11}$ (i.e., $s^{2} L_{B} C_{\mathrm{IN}}+1 \sim 0$ ), 


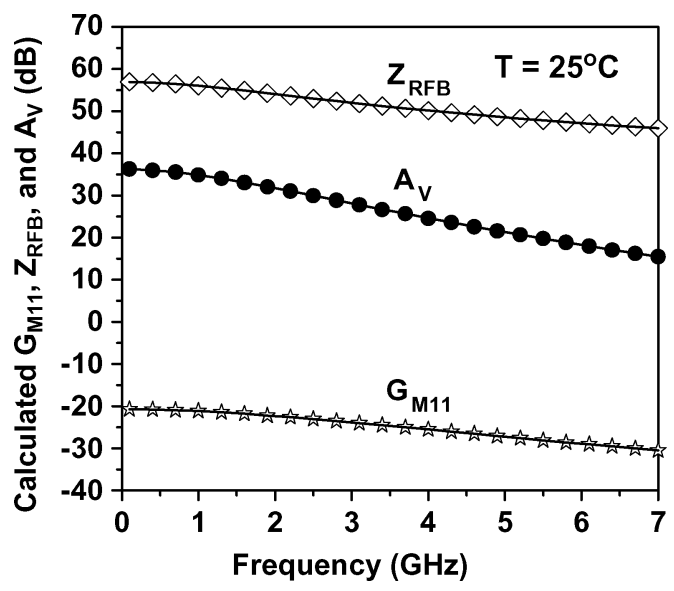

Fig. 16. Calculated $G_{M 11}, Z_{\mathrm{RFB}}$, and $A_{V}$ of the reconfigurable SiGe LNA achieved by switching bias current at the $5.2 / 5.7-\mathrm{GHz}$ mode.

$s^{2} L_{B} C_{\mathrm{IN}}+1+2 s C_{\mathrm{IN}} R_{\mathrm{IN}} \approx 2 s C_{\mathrm{IN}} R_{\mathrm{IN}}$ can be assumed, which in turn results in

$$
\begin{aligned}
G_{M 11} & =\frac{g_{m 1}}{s^{2} L_{B} C_{\mathrm{IN}}+1+2 s C_{\mathrm{IN}} R_{\mathrm{IN}}} \approx \frac{g_{m 1}}{2 s C_{\mathrm{IN}} R_{\mathrm{IN}}} \\
& \approx \frac{I_{C 1} / V_{\mathrm{T}}}{2 s R_{\mathrm{IN}}\left[C_{B E 1}+C_{B C 1}\left(1+R_{L}^{\prime} \cdot I_{C 1} / V_{\mathrm{T}}\right)\right]} .
\end{aligned}
$$

Apparently, the increase of $G_{M 11}$ resulting from the increase of $g_{m 1}$ with the increase of $I_{C 1}$ is partly counterbalanced by the increase of $C_{\mathrm{IN}}$ with the increase of $I_{C 1}$. This explains why the tuning range of $A_{v}$ for the reconfigurable LNA in Fig. 3(a) is not good. This is in contrast to CMOS LNAs [10], [17], which exhibit good tuning range due to the weak bias-current dependence of $C_{\mathrm{IN}}$.

\section{ACKNOWLEDGMENT}

The authors would like to thank the Nanodevice Laboratory (NDL) for test support, and Chip Implementation Center (CIC) for chip fabrication.

\section{REFERENCES}

[1] T. Antes and C. Conkling, "RF chip set fits multimode cellular/PCS handsets," Microwave RF, pp. 177-186, Dec. 1996.

[2] S. Wu and B. Razavi, "A 900-MHz/1.8-GHz CMOS receiver for dualband applications," IEEE J. Solid-State Circuits, vol. 33, no. 12, pp. 2178-2185, Dec. 1998.

[3] R. Magoon, I. Koullias, L. Steigerwald, W. Domino, N. Vakillian, E. Ngompe, M. Damgaard, K. Lewis, and A. Molnar, "A triple-band 900/ 1800/1900 MHz low-power image-reject front-end for GSM," in Dig. Tech. Papers ISSCC, San Francisco, CA, Feb. 2001, pp. 408-409.

[4] K. L. Fong, "Dual-band high-linearity variable-gain low-noise amplifiers for wireless applications," in Dig. Tech. Papers ISSCC, San Francisco, CA, Feb. 1999, pp. 224-225.

[5] H. Hashemi and A. Hajimiri, "Concurrent dual-band CMOS low-noise amplifiers and receiver architectures," in Symp. Dig. VLSI Circuits, Kyoto, Japan, Jun. 2001, pp. 247-250.

[6] S. H. M. Lavasani, B. Chaudhuri, and S. Kiaei, "A pseudo-concurrent 0.18- $\mu$ m multiband CMOS LNA," in Symp. Dig. IEEE RFIC, Philadelphia, PA, Jun. 2003, pp. 181-184.
[7] P. W. Lee, H. W. Chiu, T. L. Hsieh, C. H. Shen, G. W. Huang, and S S. Lu, "A SiGe low-noise amplifier for 2.4/5.2/5.7 GHz WLAN applications," in Dig. Tech. Papers ISSCC, San Francisco, CA, Feb. 2003, pp. 364-465.

[8] S. S. Lu, C. C. Meng, T. W. Chen, and H. C. Chen, "The origin of the kink phenomenon of transistor scattering parameter $S_{22}$," IEEE Trans. Microw. Theory Tech., vol. 49, no. 2, pp. 333-340, Feb. 2001.

[9] R. G. Meyer and W. D. Mack, "A 1-GHz BiCMOS RF front-end integrated circuit," IEEE J. Solid-State Circuits, vol. 29, no. 3, pp. 350-355, Mar. 1994

[10] T. Wang, H. C. Chen, H. W. Chiu, Y. S. Lin, G. W. Huang, and S. S. Lu, "Micromachined CMOS LNA and VCO by CMOS compatible ICP deep trench technology," IEEE Trans. Microw. Theory Tech., vol. 54, no. 2, pp. 580-588, Feb. 2006.

[11] K. Chang, I. Bahl, and V. Nair, RF and Microwave Circuit and Component Design for Wireless Systems. New York: Wiley, 2002, pp. 279-283.

[12] B. Razavi, RF Microelectronics. Englewood Cliffs, NJ: Prentice-Hall, 1998, p. 169.

[13] M. L. Edwards and J. H. Sinsky, "A new criterion for linear 2-port stability using a single geometrically derived parameter," IEEE Trans. Microw. Theory Tech., vol. 40, no. 12, pp. 2303-2311, Dec. 1992.

[14] T. Schwanenberger, M. Ipek, S. Roth, and H. Schemmann, "A multistandard single-chip transceiver covering 5.15 to $5.85 \mathrm{GHz}$," in Dig. Tech. Papers ISSCC, San Francisco, CA, Feb. 2003, pp. 350-351.

[15] Y. S. Lin and S. S. Lu, "An analysis of small-signal substrate resistance effect in deep-submicrometer RF MOSFETs," IEEE Trans. Microw. Theory Tech., vol. 51, no. 5, pp. 1534-1539, May 2003.

[16] A. S. Sedra and K. C. Smith, Microelectronic Circuits, 5th ed. New York: Oxford University Press, 2004, pp. 1103-1105.

[17] H. W. Chiu, S. S. Lu, and Y. S. Lin, "A $2.17 \mathrm{~dB}$ NF, 5-GHz band monolithic CMOS LNA with $10 \mathrm{~mW}$ dc power consumption on a thin $(20-\mu \mathrm{m})$ substrate," IEEE Trans. Microw. Theory Tech., vol. 53, no. 3, pp. 813-824, Mar. 2005

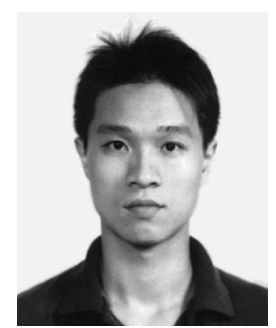

Yu-Che Yang was born in Taipei, Taiwan, R.O.C., in 1980. He received the B.S. degree in electrical engineering from National Taiwan University, Taipei, Taiwan, R.O.C., in 2002, where he is currently working toward the Ph.D. degree in electronic engineering.

His research interests include phase-locked loops, mixed-signal integrated circuits (ICs), and RF front-end ICs for wireless communications.

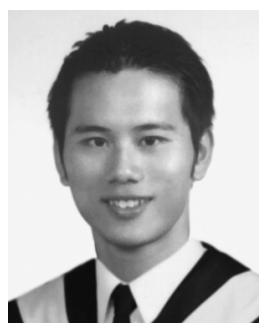

Po-Wei Lee was born in Taipei, Taiwan, R.O.C., in 1978. He received the B.S., and M.S. degrees from National Taiwan University, Taipei, Taiwan, R.O.C., in 2000 and 2002, respectively, both in electrical engineering.

In 2003, he joined the Airoha Technology Corp., a fabless RF IC design house in Taiwan, R.O.C., as an engineer. Since then, he has been involved in the area of RF circuit design.

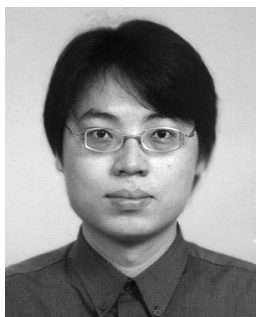

Hung-Wei Chiu was born in Taipei, Taiwan, R.O.C., in 1976. He received the B.S. degree from National Chiao-Tung University, Hsinchu, Taiwan, R.O.C., and the M.S. and Ph.D. degrees from National Taiwan University, Taipei, Taiwan, R.O.C., all in electrical engineering, in 1998, 2000 and 2003, respectively.

In 2004, he joined Taiwan Semiconductor Manufacturing Company as a designer of Mixed-Mode and RF Library Division. Since then he has worked in the area of the automation of Mixed-Mode and RF circuit 
design. In August 2005, he joined the Department of Electronic Engineering and Graduate Institute of Computer and Communication Engineering, National Taipei University of Technology, Taipei, Taiwan, R.O.C., where he is currently an Assistant Professor.

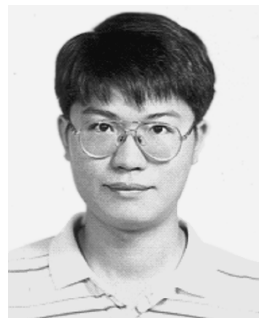

Yo-Sheng Lin (M'02-SM'06) was born in Puli, Taiwan, R.O.C., on Oct. 10, 1969. He received the $\mathrm{Ph} . \mathrm{D}$. degree in electrical engineering from the National Taiwan University, Taipei, Taiwan, R.O.C., in 1997. His Ph.D. degree was on fabrication and study of $\mathrm{GaInP} / \mathrm{InGaAs} / \mathrm{GaAs}$ doped-channel field-effect-transistors and their applications on monolithic microwave integrated circuits (MMICs).

He joined Taiwan Semiconductor Manufacturing Company (TSMC) in 1997 as a Principal Engineer for $0.35 / 0.32-\mu \mathrm{m}$ DRAM and $0.25-\mu \mathrm{m}$ embedded DRAM technology developments in Integration Department of Fab-IV. Since 2000 , he is responsible for $0.18 / 0.15 / 0.13-\mu \mathrm{m}$ CMOS low-power device technology development in Department of Device Technology and Modeling, R\&D, and promoted as Technical Manager in 2001. In August 2001, he joined the Department of Electrical Engineering, National Chi Nan University, Puli, Taiwan, R.O.C., where he is currently a Professor. From June to September, 2004, he was a Visiting Researcher at the High Speed Electronics Research Department, Bell Laboratories, Lucent Technologies, Murray Hill, NJ. His current research interests are in the areas of characterization and modeling of RF active and passive devices (especially 30-100-GHz interconnections, inductors and transformers for millimeter-wave (Bi)CMOS integrated circuits), and radio-frequency integrated circuits (RFICs)/monolithic microwave integrated circuits (MMICs).

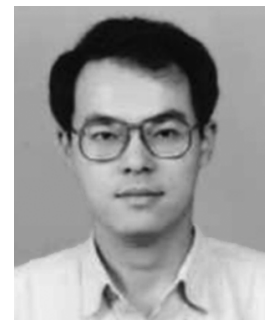

Guo-Wei Huang (S'94-M'97) was born in Taipei, Taiwan, R.O.C., in 1969. He received the B.S. degree in electronics engineering and the Ph.D. degree from National Chiao-Tung University, Hsinchu, Taiwan, R.O.C., in 1991 and 1997, respectively.

In 1997, he joined National Nano Device Laboratories, Hsinchu, Taiwan, R.O.C., where he is currently a Researcher. His current research interests focus on microwave device design, characterization and modeling.

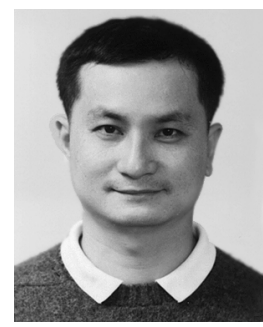

Shey-Shi Lu (S'89-M'91-SM'99) was born in Taipei, Taiwan, R.O.C., on October 12, 1962. He received the B.S. degree from the National Taiwan University, Taipei, Taiwan, R.O.C., in 1985, the M.S. degree from Cornell University, Ithaca, NY, in 1988, and the Ph.D. degree from the University of Minnesota at Minneapolis-St. Paul, in 1991, all in electrical engineering. His M.S. thesis was related to the planar doped barrier hot electron transistor, while his doctoral dissertation concerned the uniaxial stress effect on the $\mathrm{AlGaAs} / \mathrm{GaAs}$ quantum well/barrier structures.

In August 1991, he joined the department of Electrical Engineering, National Taiwan University, where he is currently a Professor. His current research interests are in the areas of radio-frequency integrated circuit (RFIC)/monolithic microwave integrated circuits (MMICs), and micromachined RF components. 